\title{
Public Trust, Information Sources and Vaccine Willingness Related to the COVID-19 Pandemic in a Caribbean Country
}

Loren De Freitas ( $\sim$ lorendefreitas@gmail.com )

:Researchers https://orcid.org/0000-0002-8431-5311

Damion Basdeo

Eastern Regional Health Authority

Han-i Wang

University of York Department of Health Sciences

\section{Research Article}

Keywords: COVID-19, vaccines, public health, public trust, Caribbean

Posted Date: March 16th, 2021

DOI: https://doi.org/10.21203/rs.3.rs-300452/v1

License: (c) (i) This work is licensed under a Creative Commons Attribution 4.0 International License.

Read Full License 


\section{Abstract}

\section{Background}

Evaluating public trust and vaccine willingness may contribute to the effectiveness of pandemic response policies and plans. This is particularly important in developing countries, such as those in the Caribbean region. This study aimed to evaluate public trust in information sources, confidence in institutions and COVID-19 vaccine willingness in Trinidad and Tobago.

\section{Methods}

A cross-sectional online survey was conducted amongst the general population in Trinidad and Tobago from November $10^{\text {th }}$ to December $7^{\text {th }} 2020$. The survey instrument was a validated questionnaire developed by the World Health Organisation (WHO) and adapted to the local setting. Descriptive statistics and regression analyses were used to analyse the data.

\section{Results}

Of the 623 responses analysed, $46.2 \%$ thought they were likely to contract COVID- 19 while $37.7 \%$ considered themselves at high risk of contracting the illness. The most trusted sources of information included health workers (53.9\%) and the ministry of health (42.4\%). Each one unit increase in trust in the medical sector lowered the odds of believing misinformation and conspiracy theories. Overall, $62.6 \%$ of respondents said they would take the COVID-19 vaccine if available and recommended. Regression analyses showed those who agreed that everyone should adhere to the national immunization schedule and those who would take the flu vaccine, were $2.92(p<0.001)$ and 3.68 times $(p<0.001)$ as likely to take the vaccine, respectively.

\section{Conclusion}

Our study found that increasing trust in health sources, confidence in medical sector, adherence to the national immunisation schedule and acceptance of the flu vaccine may increase COVID-19 vaccine willingness rates. These results may guide public health response activities and identify areas for prioritisation and improvement.

\section{Introduction}

On March 11th 2020 the World Health Organisation (WHO) declared COVID-19 a pandemic [1]. Currently, at the time of writing, there are more than 100 million confirmed cases and more than 2 million deaths globally [2]. Alongside this pandemic is the occurrence of a parallel emergency, termed the 'COVID-19 infodemic'. The term infodemic refers to an overabundance of information which may or may not be accurate [3]. Subsequently, this may lead to issues surrounding trust, reliability and willingness of populations to comply with guidelines $[3,4]$. 
The response of populations to public health measures may rely on the degree to which the population trusts the sources of information as well as institutions $[5,6]$. In the Democratic Republic of the Congo, during the Ebola virus outbreak in 2018, a lack of trust, misinformation and inaccuracy hampered early efforts to control the spread of the disease [6]. Similar patterns are also being observed with the COVID19 pandemic [7]. Given the increased global interconnectivity, the use of social media and the global scale of COVID-19, the risks associated with mistrust and misinformation may be greater than previous health emergencies [7].

Exploring the factors influencing the risk perceptions and the level of public trust and confidence that exists in populations is important to a country's pandemic response. A global effort is required to end the current pandemic. Therefore, evaluating a populations' willingness to take vaccines, especially a COVID19 vaccine, may help to tailor public health measures and health promotion in order to increase vaccine uptake [8]. The WHO technical advisory group on behavioural insights and science for health identified political decision makers, immunization programme managers, community and religious leaders, health workers, media outlets and digital platforms as groups that influence vaccinations in populations [9].

Trinidad and Tobago is a twin island developing country in the Caribbean. Currently, the country has a cumulative total of more than 7,097 positive cases of COVID-19 with a total of 125 deaths [10]. The country is currently preparing to begin its COVID-19 vaccination campaign. No previous published studies explored public trust and vaccine willingness during pandemics and public health emergencies in Trinidad and Tobago or the wider Caribbean. This study therefore aims to assess the levels of public trust in information sources, institutions and COVID-19 vaccine willingness in Trinidad and Tobago.

\section{Methodology}

\section{Study design and participants}

The study was conducted across the general population in Trinidad and Tobago. A cross-sectional survey design was used. A 15-20 minute online questionnaire was disseminated from 10th November 2020 to 7th December 2020, approximately ten months after the first case was detected in the country.

The survey instrument was a validated questionnaire developed by the World Health Organisation (WHO) [11]. The questionnaire was originally developed in Germany and validated through six rounds of data collection in Germany and assessed multiple variables. As per the WHO protocol, the questionnaire focused on variables considered important and relevant to the local pandemic. The adapted survey consisted of 36 closed ended questions across 8 main sections: socio-demographics, COVID-19 personal experience, health literacy, COVID-19 risk perception, information sources, confidence in institutions, misinformation and conspiracies, testing and tracing and vaccines (Supplementary file 1).

Participation was voluntary, anonymous and confidential and no compensation was provided.

Participants included anyone over the age of 18 years, inclusive of nationals and non-nationals, residing in Trinidad and Tobago during the pandemic period. Assuming the population size of $1,400,000,5 \%$ 
margin of error, $95 \%$ confidence interval and a $50 \%$ vaccine acceptance rate, the calculated sample size was 385 participants. However, to ensure a representative sample, the sample size was increased by $20 \%$ and a further $10 \%$ to compensate for incomplete responses, duplicate responses or those not meeting the inclusion criteria. Thus, the final calculated sample size was 500 . Ethical approval was obtained from the Ministry of Health of Trinidad and Tobago.

\section{Data collection}

The questionnaire was adapted to the local setting and piloted on a sample of 20 participants. The pilot focused on an understanding of the questions and facilitated the recognition of concerns related to survey responses. Minor adjustments to the survey responses were made after the pilot. Face to face survey interviews were not conducted in accordance with the local guidance related to the pandemic. The survey was self-administered using an online platform, Google Forms. A pragmatic approach using convenience sampling and snowballing was used to access as many participants as possible. The survey was distributed using multiple social media platforms including Whatsapp, Twitter, Linkedln and Facebook. The survey was also disseminated using professional networks.

\section{Patient and public involvement}

Patient and public involvement in research (PPI) has been defined as research being carried out 'with' or 'by' members of the public rather than 'to', 'about' or 'for' them [12]. This study incorporated the PPI concept by involving one public representative in the research process. This representative advised the research team on the design of the data collection tool and information sheets and assisted with the distribution of the data collection tool.

\section{Statistical approach}

The WHO protocol provided a statistical analysis template with pre-determined codes of descriptive and regression analyses using $\mathrm{R}$ programme language. These were adjusted to match the modifications in the questionnaire. Descriptive data collected from the questionnaire were analysed using the Statistical Package for the Social Sciences, Version 23 (SPSS 23 for Windows) and regression analyses were performed using R version 3.6.0.

Frequencies were calculated to describe data on demographics, behaviour related to COVID-19 personal experience, risk perception, getting tested, contact tracing and vaccines. Frequencies were also presented for trust and confidence in information and institutions and misinformation and conspiracies. The seven point Likert-type scale responses were re-grouped into five points for ease of presentation.

Regression analyses were used to investigate the factors that affect the risk perceptions, belief in misinformation and conspiracies and willingness to be tested, to share contacts and vaccinated using the backward elimination approach. The best models were presented. The full models contained the following predictors/variables: age, gender, education, chronic disease, health literacy, trust in institutions, trust in the medical sector, trust in media sources, being infected with COVID-19, knowing someone who was infected with COVID-19, being a health professional and frequency of media consumption. Variables 
like trust in information sources, trust in institutions, health literacy, belief in misinformation and belief in conspiracies were treated as continuous variables, using a mean score. Linear regression was applied to evaluate factors influencing belief in misinformation and conspiracies. Ordinal logistic regressions were applied to evaluate factors influencing risk perception and willingness to be vaccinated with the COVID19 vaccine. Binary logistic regression was applied to evaluate factors influencing testing and tracing. Mean estimates and odds ratios were calculated for the linear and logistic regressions respectively. Confidence intervals of $95 \%$ were also calculated and $p$ values $<0.05$ were considered significant.

\section{Results}

\section{Respondent characteristics and COVID-19 Personal Experience}

A total of 642 responses were received during the study period. Of these, 19 responses were excluded as they either did not meet inclusion criteria (11) or were duplicate responses (8). Therefore, 623 responses were analysed. The majority of participants were nationals of Trinidad and Tobago. The mean age was 31 years with most participants in the $18-29$ age category $(n=331 ; 53.1 \%)$ and $31.5 \%(n=196)$ of the sample were health professionals. The characteristics of the respondents are presented in Table 1.

Approximately $97 \%(n=603)$ of the respondents were not previously infected with COVID-19. Of those who said they were previously infected with COVID-19, 85.0\% $(n=17)$ classified it as mild and $15.0 \%(n=$ 3) classified it as severe. Only $55.0 \%(n=11)$ stated that the infection was confirmed by a test. When participants were asked if anyone in their immediate social environment had been infected by COVID-19, $35.0 \%(n=218)$ said yes. Of these participants, 27.5\% $(n=60)$ knew someone who died from COVID-19. 
Table 1

Characteristics of Respondents

\begin{tabular}{|c|c|c|}
\hline Variable & Number $(\mathrm{N})$ & Percentage (\%) \\
\hline \multicolumn{3}{|l|}{ Nationality } \\
\hline Trinidad and Tobago & 618 & 99.2 \\
\hline Other & 5 & 0.8 \\
\hline \multicolumn{3}{|l|}{ Gender } \\
\hline Male & 210 & 33.7 \\
\hline Female & 413 & 66.3 \\
\hline \multicolumn{3}{|l|}{ Age } \\
\hline $18-29$ & 331 & 53.1 \\
\hline $30-39$ & 183 & 29.4 \\
\hline $40-49$ & 49 & 7.9 \\
\hline $50-59$ & 38 & 6.1 \\
\hline Over 60 & 17 & 2.7 \\
\hline \multicolumn{3}{|l|}{ Level of Education } \\
\hline University & 523 & 83.9 \\
\hline Secondary & 48 & 7.7 \\
\hline Primary & 1 & 0.2 \\
\hline Technical/Vocational & 37 & 5.9 \\
\hline Other & 14 & 2.2 \\
\hline \multicolumn{3}{|l|}{ Healthcare Professional } \\
\hline Health-related & 196 & 31.5 \\
\hline Not Health-related & 427 & 68.5 \\
\hline \multicolumn{3}{|l|}{ Chronic Illness } \\
\hline Yes & 68 & 10.9 \\
\hline No & 520 & 83.5 \\
\hline Do not know & 35 & 5.6 \\
\hline \multicolumn{3}{|l|}{ County } \\
\hline Caroni & 142 & 22.8 \\
\hline
\end{tabular}




\begin{tabular}{|lll|}
\hline Variable & Number $(\mathbf{N})$ & Percentage (\%) \\
\hline Mayaro & 18 & 2.9 \\
\hline Nariva & 7 & 1.1 \\
\hline St.Andrews & 69 & 11.1 \\
\hline St. David & 8 & 1.3 \\
\hline St. George & 168 & 27.0 \\
\hline St. Patrick & 42 & 6.7 \\
\hline Victoria & 160 & 25.7 \\
\hline Tobago & 9 & 1.4 \\
\hline Financial Situation & & \\
\hline Improved & 57 & 9.1 \\
\hline Remained the same & 356 & 57.1 \\
\hline Worse & 193 & 31.0 \\
\hline Do not know & 17 & 2.7 \\
\hline
\end{tabular}

\section{Risk Perceptions and Health Literacy levels}

When asked about the probability of contracting COVID-19, 46.2\% $(n=288)$ of respondents thought they were likely to contract it while $37.7 \%(n=235)$ considered themselves at high risk of contracting the illness. Approximately 35\% $(n=217)$ felt they would develop severe illness if they did contract COVID-19. Ordinal logistic regression analyses are presented in Table 2. Females were more likely to think they would develop severe disease if they did have COVID-19 (odds ratio $=1.52, p=0.006$ ). Those who were not health professionals perceived that they were seven times more likely to contract COVID-19 compared to those who were health professionals (odds ratio $=7.10, p<0.001$ ). Compared to those without chronic disease, those with chronic diseases were three times more likely to think they would develop severe disease if they contracted COVID-19 (odds ratio $=3.41, p<0.001$ ). Compared to those with no or secondary school education, those with university level education considered their chances of contracting COVID-19 to be less likely (odds ratio $=0.05, p=0.011$ ) and were twice as likely to think they were at risk of getting COVID-19 (odds ratio $=2.20, p=0.006$ ).

Health literacy was assessed by asking five questions related to ease of finding and understanding COVID-19 related information. The most common response to the questions was 'easy' (supplementary Table 1).

\section{Trust in information sources and confidence in institutions}


When asked how often they sought information related to COVID-19, 25.3\% of respondents said they searched for information often/very often. Supplementary Tables 2 and 3 present results on trust in information sources and confidence in institutions. The most trusted sources of information were those related to the health sector, with most trust placed in the health workers $(n=336 ; 53.9 \%)$ and ministry of health $(n=264 ; 42.4 \%)$. Respondents were moderately confident that health institutions were capable of managing the COVID-19 pandemic (Hospitals: $n=297,47.7 \%$; Ministry of Health: $n=266,42.7 \%$ ) with low confidence levels in schools $(n=254,40.8 \%)$ and public transportation $(n=272,43.7 \%)$ 
Table 2

Factors associated with probability, risk and severity of COVID-19

\begin{tabular}{|c|c|c|c|c|c|c|}
\hline & Probability & & Severity & & Risk & \\
\hline \multirow[t]{2}{*}{ Predictors } & $\begin{array}{l}\text { Odds } \\
\text { Ratios }\end{array}$ & $\begin{array}{l}P \\
\text { value }\end{array}$ & $\begin{array}{l}\text { Odds } \\
\text { Ratios }\end{array}$ & $\begin{array}{l}P \\
\text { value }\end{array}$ & $\begin{array}{l}\text { Odds } \\
\text { Ratios }\end{array}$ & $\begin{array}{l}\mathrm{P} \\
\text { value }\end{array}$ \\
\hline & $(95 \% \mathrm{Cl})$ & & $(95 \% \mathrm{Cl})$ & & $\begin{array}{l}(95 \% \\
\mathrm{Cl})\end{array}$ & \\
\hline $\begin{array}{l}\text { Level of Education (Non- } \\
\text { university) }\end{array}$ & $\begin{array}{l}0.36 \\
(0.18-0.73)\end{array}$ & 0.005 & $\begin{array}{l}2.35 \\
(1.14- \\
4.84)\end{array}$ & 0.021 & $\begin{array}{l}2.50 \\
(1.17- \\
5.34)\end{array}$ & 0.002 \\
\hline $\begin{array}{l}\text { Level of Education (university or } \\
\text { higher) }\end{array}$ & $\begin{array}{l}0.50 \\
(0.29- \\
0.85)\end{array}$ & 0.011 & $\begin{array}{l}1.11 \\
(0.66- \\
1.88)\end{array}$ & 0.691 & $\begin{array}{l}2.20 \\
(1.26- \\
3.86)\end{array}$ & 0.006 \\
\hline $\begin{array}{l}\text { Not knowing someone in your } \\
\text { immediate social network who has } \\
\text { or had COVID-19 }\end{array}$ & $\begin{array}{l}1.45 \\
(1.07- \\
1.97)\end{array}$ & 0.016 & $\begin{array}{l}1.41 \\
(1.05- \\
1.89)\end{array}$ & 0.024 & $\begin{array}{l}0.61 \\
(0.45- \\
0.82)\end{array}$ & 0.001 \\
\hline $\begin{array}{l}\text { Never being infected with COVID- } \\
19\end{array}$ & $\begin{array}{l}2.84 \\
(1.27- \\
6.37)\end{array}$ & 0.011 & & & & \\
\hline $\begin{array}{l}\text { Trust in institutions to manage } \\
\text { COVID-19 }\end{array}$ & $\begin{array}{l}1.25 \\
(1.11- \\
1.40)\end{array}$ & $\begin{array}{l}< \\
0.001\end{array}$ & $\begin{array}{l}0.85 \\
(0.76- \\
0.96)\end{array}$ & 0.006 & $\begin{array}{l}0.88 \\
(0.78- \\
0.98)\end{array}$ & 0.023 \\
\hline Frequency of information use & $\begin{array}{l}0.93 \\
(0.85- \\
1.02)\end{array}$ & 0.146 & & & & \\
\hline Not being a health professional & $\begin{array}{l}7.10 \\
(5.03- \\
10.11)\end{array}$ & $<.001$ & $\begin{array}{l}1.31(0.96- \\
1.79)\end{array}$ & 0.087 & $\begin{array}{l}0.16 \\
(0.11- \\
0.22)\end{array}$ & ¿. 001 \\
\hline Gender (Female) & $\begin{array}{l}1.30 \\
(0.96- \\
1.75)\end{array}$ & 0.092 & $\begin{array}{l}1.52 \\
(1.13- \\
2.05)\end{array}$ & 0.006 & & \\
\hline Having a chronic illness & & & $\begin{array}{l}3.41 \\
(2.17- \\
5.40)\end{array}$ & $<.001$ & & \\
\hline Age & & & & & $\begin{array}{l}1.02 \\
(1.00- \\
1.03)\end{array}$ & 0.010 \\
\hline
\end{tabular}

\section{Belief in Misinformation and Conspiracies}

Details on COVID-19 misinformation and conspiracies are presented in supplementary Tables 4 and 5 . The most common response to all questions related to COVID-19 misinformation was 'very untrue of 
what they believe'. Approximately $50 \%(n=309)$ of respondents believed that it was probably true that 'many important things happen which the public are not aware of' and $47.8 \%(n=298)$ felt that it was probably true that 'politicians usually did not tell their true motives for doing things'. Based on the linear regression analyses, compared to those with no or secondary school or non-university education level, those with university level education were less likely to believe in misinformation and conspiracies. Each one unit increase in level of trust in the medical sector lowered the level of believing misinformation and conspiracy theories by 0.15 and 0.11 mean score points, respectively $(p<0.001$ and $p=0.001$, respectively). Each one unit increase in age decreased the level of believing in conspiracies by 0.02 mean score points $(p=0.001)$ (Table 3$)$.

Table 3

Factors associated with belief in Misinformation and Conspiracies

\begin{tabular}{|c|c|c|c|c|}
\hline \multirow[b]{2}{*}{ Predictors } & \multicolumn{2}{|c|}{ Misinformation } & \multicolumn{2}{|l|}{ Conspiracy } \\
\hline & $\begin{array}{l}\text { Estimates } \\
(95 \% \mathrm{Cl})\end{array}$ & $\begin{array}{l}P \\
\text { value }\end{array}$ & $\begin{array}{l}\text { Estimates } \\
(95 \% \mathrm{Cl})\end{array}$ & $\begin{array}{l}P \\
\text { value }\end{array}$ \\
\hline Education level (Non-university) & $\begin{array}{l}0.37(-0.03- \\
0.76)\end{array}$ & 0.068 & $\begin{array}{l}0.17(-0.63- \\
0.28)\end{array}$ & 0.454 \\
\hline Education level (university or higher) & $\begin{array}{l}-0.19(-0.49- \\
0.10)\end{array}$ & 0.195 & $\begin{array}{l}-0.36 \\
(-0.69--0.02)\end{array}$ & 0.036 \\
\hline $\begin{array}{l}\text { Trust in non-medical institutions to manage COVID- } \\
19\end{array}$ & $\begin{array}{l}0.23 \\
(0.15-0.31)\end{array}$ & $\dot{0} 001$ & & \\
\hline Trust in medical institutions to manage COVID-19 & $\begin{array}{l}-0.15 \\
(-0.22--0.08)\end{array}$ & $\hat{0} 001$ & $\begin{array}{l}-0.11 \\
(-0.18--0.05)\end{array}$ & 0.001 \\
\hline Health Literacy & $\begin{array}{l}0.16(0.10- \\
0.23)\end{array}$ & $\hat{0.001}$ & & \\
\hline Not a health professional & $\begin{array}{l}0.43(0.26- \\
0.60)\end{array}$ & $<.001$ & & \\
\hline Age & & & $\begin{array}{l}-0.02 \\
(-0.03--0.01)\end{array}$ & 0.001 \\
\hline Having a chronic illness & & & $\begin{array}{l}-0.32 \\
(-0.62--0.03)\end{array}$ & 0.030 \\
\hline $\begin{array}{l}\text { Not knowing someone in your immediate social } \\
\text { network who has or had COVID-19 }\end{array}$ & & & $\begin{array}{l}-0.25 \\
(-0.44--0.06)\end{array}$ & 0.011 \\
\hline Never being infected with COVID-19 & $\begin{array}{l}-0.33(-0.77- \\
0.11)\end{array}$ & 0.145 & $\begin{array}{l}0.40 \\
(-0.11-0.92)\end{array}$ & 0.122 \\
\hline
\end{tabular}

\section{Getting tested for COVID-19 and sharing names of contacts}


When asked if they would get tested if exposed to COVID-19 and if they would share names of contacts if tested positive for COVID-19, 83.5\% $(n=520)$ of respondents stated they would get tested and $93.7 \%(n=$ 584) stated they would share names of contacts.

The top two reasons given for why they would not get tested were 'testing would be painful' $(\mathrm{n}=38$, $38.0 \%)$ and 'getting tested would cost money' $(\mathrm{n}=33,33.0 \%)$. When asked for reasons why they would get tested for COVID-19, the top two reasons were: 'this way I can protect other people' $(\mathrm{n}=442,85.3 \%)$ and 'this is my responsibility as a citizen' $(\mathrm{n}=380,73.4 \%)$. The top two reasons for respondents sharing names of contacts, were 'this way I can protect other people' $(\mathrm{n}=527,90.5 \%)$ and 'I believe this helps stop the spread of COVID-19' $(\mathrm{n}=499,85.7 \%)$. When asked for reasons why they would not share names of contacts, the top two reasons were 'I do not trust the authorities' $(\mathrm{n}=19,50 \%)$ and 'I would cause inconvenience for those people whose names are shared' $(n=19,50 \%)$. The results for these questions are presented in supplementary tables 6 and 7 .

Based on the logistic regression analyses, those with chronic diseases were almost three times as likely to get tested compared to those without chronic diseases (odds ratio $=2.85, p=0.025$ ). For every one unit increase in trust in the medical sector, the odds of sharing names of contacts was twice as likely (odds ratio $=1.99, p<0.001)$. (Table 4). 
Table 4

Factors associated with getting tested for COVID-19 and sharing names of contacts

\begin{tabular}{|c|c|c|c|c|}
\hline & Testing & & Tracing & \\
\hline Predictors & $\begin{array}{l}\text { Odds } \\
\text { Ratio } \\
(95 \% \mathrm{Cl})\end{array}$ & $\begin{array}{l}P \\
\text { value }\end{array}$ & $\begin{array}{l}\text { Odds Ratio } \\
(95 \% \mathrm{Cl})\end{array}$ & $\begin{array}{l}\mathrm{P} \\
\text { value }\end{array}$ \\
\hline Age & $\begin{array}{l}0.98(0.95- \\
1.00)\end{array}$ & 0.037 & $\begin{array}{l}1.04 \\
(1.00- \\
1.08)\end{array}$ & 0.095 \\
\hline Education level (Non-university) & $\begin{array}{l}2.49 \\
(0.74- \\
8.88)\end{array}$ & 0.145 & & \\
\hline Education level (university or higher) & $\begin{array}{l}0.93 \\
(0.38- \\
2.05)\end{array}$ & 0.865 & & \\
\hline Having a chronic illness & $\begin{array}{l}2.85 \\
(1.23- \\
7.82)\end{array}$ & 0.025 & & \\
\hline $\begin{array}{l}\text { Not knowing someone in your immediate social } \\
\text { network who has or had COVID-19 }\end{array}$ & $\begin{array}{l}2.32 \\
(1.48- \\
3.64)\end{array}$ & $<.001$ & & \\
\hline Trust in medical institutions to manage COVID-19 & $\begin{array}{l}1.44 \\
(1.24- \\
1.68)\end{array}$ & $<001$ & $\begin{array}{l}1.99 \\
(1.57- \\
2.56)\end{array}$ & ¿. 001 \\
\hline $\begin{array}{l}\text { Frequency of media } \\
\text { consumption }\end{array}$ & $\begin{array}{l}1.21 \\
(1.05- \\
1.42)\end{array}$ & 0.012 & & \\
\hline Never being infected with COVID-19 & & & $\begin{array}{l}11.41 \\
(3.48- \\
35.02)\end{array}$ & ¿. 001 \\
\hline
\end{tabular}

\section{COVID-19 vaccine decisions}

Overall, $62.6 \%(n=390)$ of respondents said they would take the vaccine if available and recommended (37.4\% agreed, $25.2 \%$ strongly agreed). In the health professionals subgroup, $61.3 \%(n=120)$ agreed they would take the vaccine if available and recommended (32.7\% agreed, $28.6 \%$ strongly agreed) while in the non-health professionals group $63.3 \%(n=270)$ said they would take the vaccine $(39.6 \%$ agreed and $23.7 \%$ strongly agreed). $76.2 \%(n=475)$ of respondents felt that everyone should be vaccinated according to the national immunization schedule and $63.4 \%(n=395)$ stated they would receive the flu vaccine. Supplementary table 8 presents further details. 
Factors influencing the decision to take the COVID-19 vaccine are presented in Table 5.Whether the vaccine had been in use for a long time with no serious adverse effects was considered extremely important by $44.0 \%(274)$ of respondents and approximately $47 \%(n=292)$ considered whether the vaccine had been in use in other countries as very important.

Table 5

Decisions influencing willingness to get vaccinated with the COVID-19 vaccine

\begin{tabular}{|c|c|c|c|c|c|}
\hline Variable & $\begin{array}{l}\text { Not } \\
\text { important } \\
\text { N (\%) }\end{array}$ & $\begin{array}{l}\text { Low } \\
\text { importance } \\
\mathbf{N}(\%)\end{array}$ & $\begin{array}{l}\text { Neutral } \\
N(\%)\end{array}$ & $\begin{array}{l}\text { Very } \\
\text { important } \\
\mathrm{N}(\%)\end{array}$ & $\begin{array}{l}\text { Extremely } \\
\text { important } \\
\mathrm{N}(\%)\end{array}$ \\
\hline $\begin{array}{l}\text { Country in which vaccine is } \\
\text { produced }\end{array}$ & $\begin{array}{l}130 \\
(20.9)\end{array}$ & $149(23.9)$ & $\begin{array}{l}83 \\
(13.3)\end{array}$ & $\begin{array}{l}190 \\
(30.5)\end{array}$ & $71(11.4)$ \\
\hline $\begin{array}{l}\text { Recommendation from my family } \\
\text { doctor }\end{array}$ & $99(15.9)$ & $106(17.0)$ & $\begin{array}{l}118 \\
(18.90)\end{array}$ & $\begin{array}{l}239 \\
(38.4)\end{array}$ & $61(9.8)$ \\
\hline Recommendation from $\mathrm{MOH}$ & 68 (10.9) & $110(17.7)$ & $\begin{array}{l}102 \\
(16.4)\end{array}$ & $\begin{array}{l}252 \\
(40.4)\end{array}$ & $91(14.6)$ \\
\hline $\begin{array}{l}\text { Whether vaccine has been in use for } \\
\text { a long time with no serious adverse } \\
\text { effects }\end{array}$ & $16(2.6)$ & $44(7.1)$ & $\begin{array}{l}47 \\
(7.5)\end{array}$ & $\begin{array}{l}242 \\
(38.8)\end{array}$ & $\begin{array}{l}274 \\
(44.0)\end{array}$ \\
\hline $\begin{array}{l}\text { Whether the vaccine has been in use } \\
\text { in other countries }\end{array}$ & $27(4.3)$ & $53(8.5)$ & $\begin{array}{l}56 \\
(9.0)\end{array}$ & $\begin{array}{l}292 \\
(46.9)\end{array}$ & $\begin{array}{l}195 \\
(31.3)\end{array}$ \\
\hline $\begin{array}{l}\text { Risk of getting infected at the time } \\
\text { the vaccine is available }\end{array}$ & $43(6.9)$ & $84(13.5)$ & $\begin{array}{l}108 \\
(17.3)\end{array}$ & $\begin{array}{l}255 \\
(40.9)\end{array}$ & $\begin{array}{l}133 \\
(21.3)\end{array}$ \\
\hline How easy it is to get the vaccine & $66(10.6)$ & $84(13.5)$ & $\begin{array}{l}101 \\
(16.2)\end{array}$ & $\begin{array}{l}260 \\
(41.7)\end{array}$ & $\begin{array}{l}112 \\
(18.0)\end{array}$ \\
\hline Whether the vaccine is free & $82(13.2)$ & $115(18.5)$ & $\begin{array}{l}113 \\
(18.1)\end{array}$ & $\begin{array}{l}211 \\
(33.9)\end{array}$ & $\begin{array}{l}102 \\
(16.4)\end{array}$ \\
\hline $\begin{array}{l}\text { Whether a high vaccine uptake } \\
\text { would lift restrictions }\end{array}$ & $\begin{array}{l}102 \\
(16.4)\end{array}$ & $115(18.5)$ & $\begin{array}{l}131 \\
(21.0)\end{array}$ & $\begin{array}{l}181 \\
(29.1)\end{array}$ & $94(15.1)$ \\
\hline
\end{tabular}

Ordinal logistic regression analyses showed those who agreed that everyone should adhere to the national immunization schedule and those who would take the flu vaccine, were $2.92(p<0.001)$ and 3.68 times $(p<0.001)$ as likely to take the vaccine, respectively (Table 6). 
Table 6

Factors associated with willingness to take the COVID-19 vaccine

\begin{tabular}{|lll|}
\hline & \multicolumn{2}{l|}{$\begin{array}{l}\text { Willingness of getting } \\
\text { Vaccinated }\end{array}$} \\
\hline Predictors & Odds Ratios $(95 \%$ & $\begin{array}{l}\mathbf{P} \\
\text { value }\end{array}$ \\
\hline Having a chronic illness & $0.63(0.40-0.98)$ & $\mathbf{0 . 0 4 0}$ \\
\hline Trust in medical institutions to manage COVID-19 & $1.20(1.07-1.34)$ & $\mathbf{0 . 0 0 2}$ \\
\hline Trust in media sources for information & $1.11(0.98-1.25)$ & 0.104 \\
\hline $\begin{array}{l}\text { Yes everyone should be vaccinated according to the national } \\
\text { immunisation schedule }\end{array}$ & $2.92(2.01-4.26)$ & $<$ \\
\hline Yes I will take the flu vaccine & & $\mathbf{0 . 0 0 1}$ \\
\hline
\end{tabular}

\section{Discussion}

This study evaluated the public trust, information sources and vaccine willingness amongst the general population of Trinidad and Tobago during the current COVID-19 pandemic. The study was conducted ten months after the start of the local epidemic at which point there was community spread in Trinidad and Tobago. As several COVID-19 vaccines have now been approved, Trinidad and Tobago, like many other countries, is preparing to vaccinate its population. The results of this study has implications for the public health and policy approach to COVID-19 in Trinidad and Tobago, particularly for the use of COVID-19 vaccines.

The results of our study showed that $62 \%$ of respondents were willing to take the COVID-19 vaccine if available and recommended and of these, only $25 \%$ strongly agreed to take the vaccine. This vaccine willingness rate is low with variable rates seen in other countries. A multi-country study examining potential COVID-19 vaccine acceptance across 19 countries, found $71.5 \%$ of respondents agreed to take the vaccine, although there was wide variation of vaccine acceptance [13]. In a recent study in the UK, $82 \%$ of respondents indicated a willingness to take the COVID-19 vaccine [14] while $64 \%$ of respondents in an early US study and $67 \%$ in a Saudi Arabian study said they would accept the vaccine $[15,16]$. However, in both the US and UK studies there were differences in minority groups. In the UK, there were higher rates of COVID-19 vaccine hesitancy (defined as a delay in or refusal of vaccination despite availability of vaccination services [17]) in Black or Black British groups ( $72 \%$ unlikely/highly unlikely to get vaccinated) and lower rates of general vaccine uptake in Black Caribbean and Black African populations ( $50 \%$ vaccine uptake). In the US study, Black Americans had lower COVID-19 vaccine acceptance rates (40\%). Adequate global vaccine uptake is an essential element in curbing the pandemic and the range of vaccine acceptance rates suggests that achieving herd immunity from vaccination may be challenging. 
In addition to low COVID-19 vaccine willingness rates in ethnic minority groups, one US survey, conducted in September 2020, found low rates amongst health professionals as well. In that study, $63 \%$ of health professionals said they would take the vaccine [18]. Our study also found similar willingness rates amongst health care professionals with $61 \%$ stating they would take the vaccine if available and recommended (approximately 29\% strongly agreeing). As COVID-19 vaccination programmes are initiated in countries, vaccination opinions may change and self-reported behaviours, willingness (or hesitancy) to receive the vaccine may not necessarily translate into actual behaviour. Therefore, alongside the technical preparations for the COVID-19 vaccine, it is also necessary to promote confidence in the vaccine through trusted institutions. We identified that higher levels of trust in the medical sector, inclusive of the Ministry of Health, were positively correlated with willingness to take the COVID-19 vaccine. This finding is consistent with studies conducted in previous health emergencies in other countries. During the H1N1 pandemic in the Netherlands, high levels of trust in the government had a positive relationship with intention to be vaccinated while during the Ebola outbreak in the Democratic Republic of the Congo, increasing trust in the government and health professionals were associated with increased acceptance of potential Ebola vaccines (1.5 times more likely to accept) $[6,19]$. The multi-country study conducted on COVID-19 vaccine acceptance noted that the higher levels of vaccine acceptance were seen in Asian countries which often had greater levels of trust in governments [13]. Addressing vaccine hesitancy may involve mass education and health promotion campaigns providing populations with accurate, reliable information on the COVID-19 vaccine, using plain, non-technical language. Conducting campaigns in areas where there are high volumes of at-risk persons, such as health centers, emergency departments, pharmacies as well as private GP officers, may be beneficial. Engaging communities, co-producing information with trusted sources, allowing individuals to voice concerns and debunk myths may allow individuals to make an informed decision as well as develop vaccine delivery plans that incorporate local needs [9].

One review exploring vaccine hesitancy amongst health professionals found that vaccinated health care professionals were more likely to recommend vaccines to patients [20]. Since respondents in our study trusted health professionals as sources of information, it is necessary to build vaccine confidence in this group by addressing their own concerns and understanding what factors influence health professionals' decision to recommend the vaccine $[9,20]$. It is important to engage the various health professional associations providing necessary support to manage vaccine hesitancy as well as raise awareness of the COVID-19 vaccine both within their profession and the general population.

Supporting the national immunisation schedule and accepting the seasonal flu vaccine were other factors positively correlated with willingness to take the COVID-19 vaccine in Trinidad and Tobago. In Trinidad and Tobago vaccines are provided without direct cost in the public health system, through the Expanded Programme on Immunisation (EPI) [21]. The World Health Organization (WHO) implemented the Expanded Programme on Immunization (EPI) in 1974 with the aim of increasing immunization coverage internationally, especially among children [22]. In the Caribbean region, between 2013 and 2017, there was a general downward trend in vaccination coverage for several routine vaccines as well as a slow uptake for newer vaccines that were added to the routine schedule (eg, HPV) [23]. However, 2019 
WHO and United Nations International Children's Emergency Fund data for Trinidad and Tobago indicated a reversal of this trend with the estimated immunisation coverage above $90 \%$ for the majority of vaccines on the national immunisation schedule [24]. While this is encouraging, it should be noted that the national immunisation programme focuses on children and is often a requirement for children to be enrolled in school [25]. In our study $76 \%$ of respondents supported the national immunisation schedule suggesting that it is still necessary to improve vaccine acceptance generally. Overall, the region should critically explore the reasons contributing to decreased vaccination coverage and develop methods to build trust in the programme. This may involve implementing transparent vaccine safety monitoring systems which may alleviate concerns regarding serious adverse effects.

The study also found that increasing levels of trust in the medical sector were associated with decreasing levels of belief in misinformation as well as a greater likelihood of getting tested and sharing names of contacts. This demonstrates the importance of public trust in managing health emergencies and is consistent with results in other settings. In the early phase of the COVID-19 pandemic in the United States, one study found higher levels of trust in government sources such as the Centers for Disease and Control (70\%) and lower levels of trust in social media (27\% Facebook) [5]. This is important for public health communicators when deciding which media to use to share information on COVID-19 as well as ensuring that these media forms share accurate and reliable information.

Most respondents in our study believed that important things happened which the public was not aware of and that politicians usually were not forthcoming with their true motives. Therefore, on-going risk communication may be beneficial in strengthening trust in institutions generally, ensuring that populations are provided with relevant, accurate information. Our study also identified that lower levels of education and health literacy were associated with increased levels of belief in misinformation. The effect of misinformation on compliance with public health measures has been demonstrated in other studies $[6,26,27]$. Although, overall the belief in misinformation was low in this study, focusing on strengthening health literacy rates in the country, correcting misinformation, implementing targeted health promotion and health education campaigns and continuing to build trust in the medical sector may support compliance with public health measures in this pandemic and future health emergencies.

\section{Study limitations}

There are several limitations that should be acknowledged. The survey was cross-sectional in nature and therefore the results are representative of that point in time. Although the survey captured responses from all counties, some areas remained underrepresented, with the majority of participants based in Trinidad. Focused surveys may be required for the island of Tobago as well as rural areas in Trinidad. As a result of resource limitations, this study was not able to specifically focus on the growing Venezuelan migrant population in Trinidad and Tobago. As migrant groups are especially vulnerable in the pandemic, a separate study should target this sub-population. 
While using the online survey format was necessary given the social distancing restrictions, the format may have limited participation from certain subsets of the population such as the elderly, those in rural areas with no internet access and those belonging to the migrant population. Using computer assisted or telephone interviews may assist with increasing participation. Although the survey attempted to provide participants with a range of responses, it would also be useful to conduct qualitative research (ensuring adherence to local restrictions) to provide a deeper understanding of the factors contributing to vaccine hesitancy.

\section{Conclusion}

This study examined public trust, information sources and vaccine willingness related to COVID-19 in Trinidad and Tobago. Our study found that increasing trust in health sources, confidence in medical sector, adherence to the national immunisation schedule and acceptance of the flu vaccine may increase COVID-19 vaccine willingness rates. These results may guide public health response activities and identify areas for prioritisation and improvement with the ultimate objective of curbing the spread of COVID-19 in the country as well as contributing to the global response to end the pandemic.

\section{Declarations}

\section{Funding:}

None

\section{Conflict of Interest:}

None to declare

\section{Ethics approval:}

was obtained from the Ministry of Health Trinidad and Tobago

\section{Consent for publication:}

not applicable

\section{Availability of data and materials:}

Authors should be contacted for data requests

\section{Acknowledgements:}

We would like to thank Darcelle Doodnath, our patient and public involvement representative for her feedback with the methods. 


\section{Author contributions:}

LD conceived the idea. LD and DB executed the study including data collection and management. HW conducted the main data analysis. LD and DB drafted the article and all authors contributed to the revision of the article. All authors approved the final version of the article.

\section{References}

1. World Health Organisation. Rolling updates on coronavirus disease (COVID-19). World Health Organization. [cited 2021 Feb 9]. Available from: https://www.who.int/emergencies/diseases/novelcoronavirus-2019

2. World Health Organization. Coronavirus disease (COVID-19) Dashboard [Internet]. World Health Organization; [cited 2021 Feb 9]. Available from: https://covid19.who.int/table

3. Pan American Health Organisation. Department of Intelligence and Evidence for Action in Health. Understanding the infodemic and misinformation in the fight against COVID-19. [Internet]. PAHO/WHO [cited 2020 Dec 5]. Available from: https://www.paho.org/en/documents/understandinginfodemic-and-misinformation-fight-against-covid-19

4. World Health Organization. An ad hoc WHO technical consultation managing the COVID-19 infodemic: call for action [Internet]. World Health Organization [cited 2020 Dec 22]. Available from: https://www.who.int/publications/i/item/9789240010314

5. Fridman I, Lucas N, Henke D, Zigler CK. Association Between Public Knowledge About COVID-19, Trust in Information Sources, and Adherence to Social Distancing: Cross-Sectional Survey [Internet]. JMIR Public Health and Surveill. JMIR Publications Inc., Toronto, Canada; [cited 2020 Dec 12]. Available from: https://publichealth.jmir.org/2020/3/e22060/

6. Vinck P, Pham PN, Bindu KK, Bedford J, Nilles EJ. Institutional trust and misinformation in the response to the 2018-19 Ebola outbreak in North Kivu, DR Congo: a population-based survey [Internet]. The Lancet. The Lancet Infectious Disease; 2019 [cited 2020 Jan 21]. Available from: https://www.thelancet.com/journals/laninf/article/PIIS1473-3099(19)30063-5/fulltext

7. Tagliabue F, Galassi L, Mariani P. The "Pandemic" of Disinformation in COVID-19 [Internet]. SN Comprehensive Clinical Medicine. Springer International Publishing; 1970 [cited 2020 Oct 10]. Available from: https://link.springer.com/article/10.1007/s42399-020-00439-1

8. Schwartz JL. Evaluating and deploying COVID-19 vaccines- the importance of transparency, scientific integrity and public [internet]. NEJM [cited 2021 Jan 22]. Available from: https://www.nejm.org/doi/full/10.1056/NEJMp2026393

9. World Health Organization. Behavioural Considerations for Acceptance and Uptake of COVID-19 Vaccines: Who Technical Advisory Group on Behavioural Insights And Sciences For Health [internet]. World Health Organisation: Geneva, Switzerland. 2020. [cited 2021 Feb 1. Available from: https://apps.who.int/iris/bitstream/handle/10665/337335/9789240016927-eng.pdf? sequence=1\&isAllowed=y 
10. Ministry of Health Government of Trinidad and Tobago. COVID-19 Update Trinidad and Tobago [Internet]. Ministry of Health., Government of Trinidad and Tobago. 2020 [cited 2021 Feb 11]. Available from: https://health.gov.tt/covid-19-news-and-updates/covid-19-update-trinidad-andtobago

11. WHO Regional Office for Europe. Survey Tool and Guidance: rapid, simple, flexible behavioural insights on COVID-19. Monitoring knowledge, risk perceptions, preventive behaviours and trust to inform pandemic outbreak response. 2020;(July):1-42. Available from: http://it.ubc.ca/services/teaching-learning-tools/survey-tool

12. National Institute of Health Research. INVOLVE. 2020. [cited Feb 28, 2021]. Available from: https://www.invo.org.uk/

13. Lazarus JV, Ratzan SC, Palayew A, Gostin LO, Larson HJ, Rabin K et al. A global survey of potential acceptance of a COVID-19 vaccine [Internet]. Nature medicine. Nature Publishing Group US; 2020 [cited 2020 Oct 20]. Available from: https://www.ncbi.nlm.nih.gov/pmc/articles/PMC7573523/

14. Scientific Advisory Group for Emergencies. Factors influencing COVID-19 vaccine uptake among minority ethnic groups-17 December 2020 [Internet]. GOV.UK. 2021 [cited 2021 Feb 1] Available from: https://www.gov.uk/government/publications/factors-influencing-covid-19-vaccine-uptake-amongminority-ethnic-groups-17-december-2020

15. Malik AA, McFadden SM, Elharake J, Omer SB. Determinants of COVID-19 vaccine acceptance in the US [Internet]. E Clinical Medicine. U.S. National Library of Medicine; [cited 2021 Jan 25]. Available from: https://pubmed.ncbi.nIm.nih.gov/32838242/

16. Al-Mohaithef M, Padhi BK. Determinants of COVID-19 Vaccine Acceptance in Saudi Arabia: A WebBased National Survey [Internet]. J Multidisc Healthc. Dove Press; 2020 [cited 2021 Jan 15]. Available from: https://www.dovepress.com/determinants-of-covid-19-vaccine-acceptance-in-saudiarabia-a-web-base-peer-reviewed-article-JMDH

17. MacDonald NE. Vaccine hesitancy: Definition, scope and determinants [Internet]. Vaccine. Elsevier; 2015 [cited 2021 Feb 5]. Available from:

https://www.sciencedirect.com/science/article/pii/S0264410X15005009?via\%3Dihub

18. Centers for Disease and Control COVID-19 Response Vaccine Task Force. Building Confidence in COVID-19 Vaccines Among Your Patients [internet]. Centers for Disease and Control. December 2020; [cited 2021 Feb 1]. Available from: https://www.cdc.gov/vaccines/covid-

19/downloads/VaccinateWConfidence-TipsForHCTeams_508.pdf

19. van der Weerd W, Timmermans DR, Beaujean DJ, Oudhoff J, van Steenbergen JE. Monitoring the level of government trust, risk perception and intention of the general public to adopt protective measures during the influenza A (H1N1) pandemic in The Netherlands [Internet]. 2011. BMC public health. U.S. National Library of Medicine; [cited 2020 Dec 11]. Available from: https://pubmed.ncbi.nlm.nih.gov/21771296/

20. Paterson P, Meurice F, Stanberry LR, Glismann S, Rosenthal SL, Larson HJ. Vaccine hesitancy and healthcare providers [Internet]. Vaccine. U.S. National Library of Medicine; 2016 [cited 2021 Feb 6]. 
Available from: https://pubmed.ncbi.nlm.nih.gov/27810314/

21. Ministry of Health Government of Trinidad and Tobago. Immunization [Internet]. Ministry of Health. 2020. [cited 2021 Feb 6]. Available from: https://health.gov.tt/services/immunization

22. Hamid H, Mallhi TH, Naseer MS, Younas I, Rashid MA, Pervaiz A, ul Ain N. The COVID-19 pandemic threatens the Expanded Program on Immunization: recommendations for sustaining vaccination goals [Internet]. Drugs \& Therapy Perspectives. Springer International Publishing; 1970 [cited 2021 Feb 8]. Available from: https://link.springer.com/article/10.1007/s40267-020-00774-2

23. Pan American Health Organisation. Thirty-Second Meeting of the Caribbean Immunization Managers [Internet]. Nov 2016 [cited 2021 Feb 7]. Available from:

https://www.paho.org/hq/dmdocuments/2017/Immunization-Caribbean-EPI-32-Mgrs-Mtg-2016e.pdf

24. World Health Organisation. Trinidad and Tobago: WHO and UNICEF estimates of immunization coverage: 2019 [internet] World Health Organisation. [cited 2021 Feb 8].Available from: https://www.who.int/immunization/monitoring_surveillance/data/tto.pdf? ua=1https://www.euro.who.int/_data/assets/pdf_file/0007/436705/COVID-19-survey-tool-andguidance.pdf

25. Ministry of the Attorney General and Legal Affairs. Laws of Trinidad and Tobago. 2015; Public Health (Nursery Schools and Primary Schools Immunisation) Act. Chapter 28:03[Internet]. December 2016 [cited 2021 Feb 2]. Available from: https://rgd.legalaffairs.gov.tt/laws2/Alphabetical_List/lawspdfs/28.03.pdf

26. Roozenbeek J, Schneider CR, Dryhurst S, Kerr J, Freeman AL, Recchia G et al. Susceptibility to misinformation about COVID-19 around the world [Internet]. Royal Society Open Science. 2020 [cited 2021 Dec 20]. Available from: https://royalsocietypublishing.org/doi/10.1098/rsos.201199

27. Ministry of Internally Displaced Persons from the Occupied Territories, Labour, Health and Social Affairs of Georgia. Knowledge, risk perceptions, preventive behaviours, and public trust in current COVID-19 outbreak [Internet]. World Health Organisation 2020 [cited 2021 Jan 31]. Available from: https://www.unicef.org/georgia/reports/knowledge-risk-perceptions-preventive-behaviours-andpublic-trust-current-covid-19-outbreak

\section{Supplementary Files}

This is a list of supplementary files associated with this preprint. Click to download.

- SupplementaryFile1.docx

- SupplementaryTables.docx 